\title{
Lack of Breastfeeding History in Parous Women with Inflammatory Breast Cancer Predicts Poor Disease-Free Survival
}

\author{
Shane R. Stecklein¹, Jay P. Reddy¹, Adam R. Wolfe1, Mirtha S. Lopez², Tamer M. Fouad3,4, Bisrat G. Debeb1, \\ Naoto T. Ueno 3,5 , Abenaa M. Brewster ${ }^{3,6}$, and Wendy A. Woodward ${ }^{1,5} \bowtie$
}

${ }^{1}$ Department of Radiation Oncology; ${ }^{2}$ Department of Epidemiology; ${ }^{3}$ Department of Breast Medical Oncology, The University of Texas MD Anderson Cancer Center, Houston, Texas, United States of America; ${ }^{4}$ Department of Medical Oncology, National Cancer Institute, Cairo University, Cairo, Egypt; 5 Morgan Welch Inflammatory Breast Cancer Research Program and Clinic; 6 Department of Clinical Cancer Prevention, The University of Texas MD Anderson Cancer Center, Houston, Texas, United States of America

$\square$ Corresponding author: Wendy A. Woodward, M.D., Ph.D., Associate Professor, Department of Radiation Oncology, Deputy Director, Morgan Welch Inflammatory Breast Cancer Research Program and Clinic, 1515 Holcombe Boulevard, Unit 1422 (FCT6.6072), Houston, TX 77030. Phone: (713) 563-2300; Fax: (713) 563-2331; E-mail: wwoodward@mdanderson.org

( ) Ivyspring International Publisher. This is an open access article distributed under the terms of the Creative Commons Attribution (CC BY-NC) license (https://creativecommons.org/licenses/by-nc/4.0/). See http://ivyspring.com/terms for full terms and conditions.

Received: 2017.03.15; Accepted: 2017.05.09; Published: 2017.07.01

\begin{abstract}
Purpose: Breastfeeding alters the breast microenvironment, and several lines of evidence suggest the breast microenvironment contributes to the clinical phenotype of inflammatory breast cancer. We investigated breastfeeding history as a modifier of locoregional recurrence (LRR), distant metastasis (DM), disease-free survival (DFS), and overall survival (OS) in parous women with inflammatory breast cancer.

Methods: Parous women with inflammatory breast cancer were identified from a prospective registry at The University of Texas MD Anderson Cancer Center. We compared patient and tumor characteristics, LRR, DM, DFS, and OS patients with (BF+) and without (BF-) a history of breastfeeding.

Results: Eighty-two patients were included. At a median follow-up of 50 months, BF+ patients had significantly lower risk of LRR (9.0\% vs. $23.6 \%$; $p=0.01)$, a lower risk of DM (26.8\% vs. $53.8 \%$; $p=0.008)$, and better DFS $(73.1 \%$ vs. $48.1 \%$; $=0.006)$ than $B F-$ patients. On multivariate analysis, $B F+$ history was associated with significantly lower risk of DM (hazard ratio $0.38,95 \%$ confidence interval $0.15-0.97$; $\mathrm{p}=0.04$ ) and better DFS (hazard ratio $0.37,95 \%$ confidence interval $0.15-0.93 ; \mathrm{p}=0.04$ ) after adjusting for established predictive and prognostic variables. The prognostic significance of breastfeeding may be most pronounced in women with triple-negative IBC.

Conclusion: A lack of breastfeeding history in parous women with inflammatory breast cancer may predict worse prognosis. We speculate that breastfeeding-induced alterations in the breast microenvironment may alter the aggressiveness of inflammatory breast cancer.
\end{abstract}

Key words: Inflammatory Breast Cancer, Breastfeeding, Microenvironment, Epidemiology

\section{Introduction}

Inflammatory breast cancer (IBC) is a unique clinical manifestation of malignant breast disease and accounts for $2 \%-4 \%$ of invasive breast cancers diagnosed in the United States. Compared with non-inflammatory breast cancer (non-IBC), IBC is associated with an aggressive clinical course and poor outcomes, even after analyses control for established predictive and prognostic factors. While the clinical manifestations of IBC differ substantially from those of non-IBC, the molecular alterations distinguishing these two entities are more subtle [1-7]. Studies have identified genomic alterations, transcriptional signatures, DNA methylation patterns, and differential expression of non-coding RNAs that are enriched in IBC compared with non-IBC [1-7], although none of these molecular platforms can 
reliably discriminate IBC from non-IBC in the clinical setting. In the absence of obvious genetic or epigenetic alterations, numerous studies have suggested that the mammary gland microenvironment plays an important role in the IBC phenotype [8].

Aside from age and family history, which are the strongest risk factors for developing breast cancer, most other established risk factors for breast cancer are related to menstrual and reproductive history. The most studied of these factors include parity, age at first pregnancy, ages at menarche and menopause, breastfeeding history, and use of exogenous hormone replacement therapy [9]. The physiologic hormonal changes that occur during puberty and especially those that occur during pregnancy and lactation result in marked architectural and cellular remodeling in the breast.

We have previously reported that in women with triple-negative breast cancer, which is the immunohistochemical subtype comprising most basal-like breast cancers, a lack of breastfeeding history or a short duration of breastfeeding was associated with the presence of cells expressing stem cell markers in adjacent normal breast tissue [10]. This association suggests that not breastfeeding may result in a persistent population of aberrant stem cells that may be the target of transformational events or, alternatively, may result in the formation of diffuse stem cell niches throughout normal breast tissue that may alter the behavior of tumor cells that arise years later [8]. Since breastfeeding history appears to permanently affect the normal mammary gland microenvironment and since IBC specifically seems to be influenced by the microenvironment, we sought to investigate the impact of breastfeeding on patterns of recurrence, metastasis, and survival in a prospectively identified cohort of parous IBC patients.

\section{Methods}

\section{Study Cohort}

A retrospective analysis was performed using a prospective registry of patients evaluated at The University of Texas MD Anderson Cancer Center who met international consensus guidelines for a diagnosis of IBC [11]. All patients seen at the MD Anderson Cancer Center Morgan Welch IBC Clinic since 2004 have been invited to participate in this registry. Patients who agreed to participate completed an in-person, interviewer-administered questionnaire focused on lifestyle, reproductive, and family factors that influence breast cancer risk. All patients were evaluated by a breast surgeon, breast medical oncologist, and breast radiation oncologist in the multidisciplinary IBC clinic. Biopsy and surgical specimens were centrally reviewed by an MD Anderson breast pathologist, and 1\% nuclear expression was used as the cutoff for estrogen receptor (ER) and progesterone receptor (PR) expression, consistent with the current recommendations from the American Society for Clinical Oncology and College of American Pathologists [12]. For our analyses, data were abstracted for patients who had a history of at least one pregnancy resulting in a live birth and were treated with mastectomy followed by adjuvant radiation therapy. These patients confirmed $(\mathrm{BF}+)$ or denied (BF-) a history of any breastfeeding. Breastfeeding history was categorized as positive if patients reported any history of breastfeeding, regardless of duration. This study was approved by the institutional review board of MD Anderson.

\section{Statistical Analysis}

Patient and tumor characteristics were compared between $\mathrm{BF}+$ and $\mathrm{BF}-$ patients using the Fisher exact test (or the Fisher-Freeman-Halton test for $2 \times 3$ contingency tables) for categorical variables and the Mann-Whitney test for continuous variables. Time to locoregional recurrence (LRR, defined as disease recurrence within the irradiated chest wall or regional lymphatics), time to distant metastasis (DM, defined as disease recurrence outside of the irradiated field), disease-free survival (DFS, defined as no LRR or DM), and overall survival (OS) were compared between $\mathrm{BF}+$ and BF- patients using the Kaplan-Meier method with the log-rank test. Cox proportional hazard models were used to estimate the hazard ratios (HRs) for risk of LRR, DM, DFS, and OS, adjusted for prognostic clinical and pathologic factors. Significance was defined as $p<0.05$. All statistical tests were two-sided, and analyses were performed in SPSS version 23. Graphs were generated using GraphPad Prism version 6 .

\section{Results}

\section{Patient, Tumor, and Treatment Characteristics}

Eighty-two patients ( $34 \mathrm{BF}$ - and $48 \mathrm{BF}+$ ) who met the criteria for inclusion were identified. Their demographic, tumor, and treatment characteristics are summarized in Table 1. For the patients who reported a positive history of breastfeeding, the median duration of breastfeeding was 5.0 months. Most patients received neoadjuvant chemotherapy, and all patients underwent mastectomy followed by post-mastectomy radiation therapy. A comparison of demographic, tumor, and treatment variables by breastfeeding history is shown in Table 2. Patients 
with a positive history of breastfeeding were younger at diagnosis (median 49.0 years vs. 53.5 years; $p=0.02$ ), older at age of first live birth (median 24.0 years vs. 20.0 years; $\mathrm{p}=0.001)$, and more likely to be white $(81 \%$ vs. $70 \% ; \mathrm{p}=0.002$ ). The distribution of breast cancer subtypes also differed between the two cohorts, with $\mathrm{BF}+$ patients being significantly more likely to have HER2+ disease (62\% vs. $27 \%$; $\mathrm{p}=0.002)$ and less likely to have triple-negative breast cancer $(13 \%$ vs. $32 \%$; $\mathrm{p}=0.05)$. The BF+ and BF- groups did not significantly differ in stage, grade, type or sequence of therapy, pathologic complete response after neoadjuvant chemotherapy, age at menarche, number of pregnancies, body mass index at diagnosis, menopausal status, or history of oral contraceptive or hormone replacement therapy use.

Table 1. Demographic, Tumor, and Treatment Characteristics

\begin{tabular}{|c|c|}
\hline Characteristic & Value $(\mathrm{N}=82)$ \\
\hline Age at Diagnosis, Median (Range) & 51 years (23-78 years) \\
\hline Median Age at Menarche, Median (Range) & 13 years ( $9-16$ years) \\
\hline Age at Parity, Median (Range) & 22 years ( $14-34$ years) \\
\hline Number of Pregnancies, Median (Range) & $2.5(1-9)$ \\
\hline Body Mass Index at Diagnosis, Median (Range) & $29.2(20.5-81.1)$ \\
\hline \multicolumn{2}{|l|}{ Race/Ethnicity, No. (\%) } \\
\hline White & $63(77 \%)$ \\
\hline Black & $7(8 \%)$ \\
\hline Other & $12(15 \%)$ \\
\hline \multicolumn{2}{|l|}{ Menopausal Status, No. (\%) } \\
\hline Pre-menopausal & $39(48 \%)$ \\
\hline Post-menopausal & $43(52 \%)$ \\
\hline \multicolumn{2}{|l|}{ Oral Contraceptive Use, No. $(\%)$} \\
\hline No & $12(15 \%)$ \\
\hline Yes & $62(75 \%)$ \\
\hline Unknown & $8(10 \%)$ \\
\hline \multicolumn{2}{|l|}{ Hormone Replacement Therapy Use, No. (\%) } \\
\hline No & $58(71 \%)$ \\
\hline Yes & $22(27 \%)$ \\
\hline Unknown & $2(2 \%)$ \\
\hline \multicolumn{2}{|l|}{ Clinical Stage, No. (\%) } \\
\hline IIIB & $50(61 \%)$ \\
\hline IIIC & $32(39 \%)$ \\
\hline \multicolumn{2}{|l|}{ Grade, No. (\%) } \\
\hline I-II & $16(20 \%)$ \\
\hline III & $65(79 \%)$ \\
\hline Unknown & $1(1 \%)$ \\
\hline \multicolumn{2}{|l|}{ Subtype, No. (\%) } \\
\hline ER/PR+, HER2- & $26(32 \%)$ \\
\hline HER2+ & $39(47 \%)$ \\
\hline Triple-Negative & $17(21 \%)$ \\
\hline \multicolumn{2}{|l|}{ Neoadjuvant Therapy, No. (\%) } \\
\hline Chemotherapy & $81(99 \%)$ \\
\hline Endocrine Therapy & $2(5 \% a)$ \\
\hline Radiation Therapy & $1(1 \%)$ \\
\hline \multicolumn{2}{|l|}{ Adjuvant Therapy, No. (\%) } \\
\hline Chemotherapy & $33(40 \%)$ \\
\hline Endocrine Therapy & $34(79 \% a)$ \\
\hline Radiation Therapy & $82(100 \%)$ \\
\hline \multicolumn{2}{|l|}{ Pathologic Complete Response, No. (\%) } \\
\hline No & $63(77 \%)$ \\
\hline Yes & $18(22 \%)$ \\
\hline Unknown & $1(1 \%)$ \\
\hline
\end{tabular}

aPercentage of patients with ER/PR+ tumors
Table 2. Comparison of Patient, Tumor, and Treatment Characteristics by Breastfeeding History

\begin{tabular}{|c|c|c|c|}
\hline Characteristic & $\begin{array}{l}\text { No } \\
\text { Breastfeeding } \\
(\mathrm{N}=34)\end{array}$ & $\begin{array}{l}\text { Breastfeeding } \\
(\mathrm{N}=48)\end{array}$ & $\mathbf{P}$ \\
\hline $\begin{array}{l}\text { Age at Diagnosis, Median } \\
\text { (Range) }\end{array}$ & $\begin{array}{l}53.5 \text { years }(27-78 \\
\text { years) }\end{array}$ & $\begin{array}{l}49 \text { years }(23-78 \\
\text { years) }\end{array}$ & 0.02 \\
\hline $\begin{array}{l}\text { Age at Menarche, Median } \\
\text { (Range) }\end{array}$ & $\begin{array}{l}13 \text { years }(10-16 \\
\text { years) }\end{array}$ & $\begin{array}{l}13 \text { years }(9-15 \\
\text { years) }\end{array}$ & 1.00 \\
\hline Age at Parity, Median (Range) & $\begin{array}{l}20 \text { years }(14-29 \\
\text { years) }\end{array}$ & $\begin{array}{l}24 \text { years }(15-34 \\
\text { years) }\end{array}$ & 0.001 \\
\hline $\begin{array}{l}\text { Number of Pregnancies, Median } \\
\text { (Range) }\end{array}$ & $3(1-9)$ & $2(1-6)$ & 0.75 \\
\hline $\begin{array}{l}\text { Body Mass Index at Diagnosis, } \\
\text { Median (Range) }\end{array}$ & $31.6(23.7-77.0)$ & $29.0(20.5-81.1)$ & 0.08 \\
\hline $\begin{array}{l}\text { Breastfeeding Duration, Median } \\
\text { (Range) }\end{array}$ & - & $\begin{array}{l}5.0 \text { months } \\
(0.5-66.0 \\
\text { months })^{c}\end{array}$ & NA \\
\hline \multicolumn{4}{|l|}{ Race/Ethnicity, No. (\%) } \\
\hline White & $24(70 \%)$ & $39(81 \%)$ & \multirow{3}{*}{0.002} \\
\hline Black & $7(21 \%)$ & $0(0 \%)$ & \\
\hline Other & $3(9 \%)$ & $9(19 \%)$ & \\
\hline \multicolumn{4}{|l|}{ Menopausal Status, No. (\%) } \\
\hline Pre-menopausal & $12(35 \%)$ & $27(56 \%)$ & \multirow[t]{2}{*}{0.08} \\
\hline Post-menopausal & $22(65 \%)$ & $21(44 \%)$ & \\
\hline \multicolumn{4}{|l|}{ Oral Contraceptive Use, No. (\%) } \\
\hline No & $4(12 \%)$ & $8(17 \%)$ & \multirow{3}{*}{$0.75^{b}$} \\
\hline Yes & $26(76 \%)$ & $36(75 \%)$ & \\
\hline Unknown & $4(12 \%)$ & $4(8 \%)$ & \\
\hline \multicolumn{4}{|l|}{$\begin{array}{l}\text { Hormone Replacement Therapy } \\
\text { Use, No. }(\%)\end{array}$} \\
\hline No & $24(71 \%)$ & $34(71 \%)$ & \multirow[t]{3}{*}{$0.80^{\mathrm{b}}$} \\
\hline Yes & $10(29 \%)$ & $12(25 \%)$ & \\
\hline Unknown & $0(0 \%)$ & $2(4 \%)$ & \\
\hline \multicolumn{4}{|l|}{ Clinical Stage, No. (\%) } \\
\hline IIIB & $23(68 \%)$ & $27(56 \%)$ & \multirow[t]{2}{*}{0.36} \\
\hline IIIC & $11(32 \%)$ & $21(44 \%)$ & \\
\hline \multicolumn{4}{|l|}{ Grade, No. (\%) } \\
\hline I-II & $4(12 \%)$ & $12(25 \%)$ & \multirow{3}{*}{$0.26^{b}$} \\
\hline III & $29(85 \%)$ & $36(75 \%)$ & \\
\hline Unknown & $1(3 \%)$ & $0(0 \%)$ & \\
\hline \multicolumn{4}{|l|}{ Subtype, No. (\%) } \\
\hline ER/PR+, HER2- & $14(41 \%)$ & $12(25 \%)$ & \multirow{3}{*}{$\begin{array}{l}0.15 \\
0.002 \\
0.05\end{array}$} \\
\hline HER2+ & $9(27 \%)$ & $30(62 \%)$ & \\
\hline Triple-Negative & $11(32 \%)$ & $6(13 \%)$ & \\
\hline \multicolumn{4}{|l|}{ Neoadjuvant Therapy, No. (\%) } \\
\hline Chemotherapy & $34(100 \%)$ & $47(98 \%)$ & 1.00 \\
\hline Endocrine Therapy & $1(6 \% a)$ & $1(4 \% a)$ & \multirow{2}{*}{$\begin{array}{l}1.00 \\
0.42\end{array}$} \\
\hline Radiation Therapy & $1(3 \%)$ & $0(0 \%)$ & \\
\hline \multicolumn{4}{|l|}{ Adjuvant Therapy, No. (\%) } \\
\hline Chemotherapy & $10(29 \%)$ & $23(48 \%)$ & \multirow{3}{*}{$\begin{array}{l}0.11 \\
0.26 \\
\text { NA }\end{array}$} \\
\hline Endocrine Therapy & $16(89 \% \mathrm{a})$ & $18(72 \% \mathrm{a})$ & \\
\hline Radiation Therapy & $34(100 \%)$ & $48(100 \%)$ & \\
\hline \multicolumn{4}{|l|}{$\begin{array}{l}\text { Pathologic Complete Response, } \\
\text { No. }(\%)\end{array}$} \\
\hline No & $28(82 \%)$ & $35(73 \%)$ & $0.43^{b}$ \\
\hline Yes & $6(18 \%)$ & $12(25 \%)$ & \\
\hline Unknown & $0(0 \%)$ & $1(2 \%)$ & \\
\hline
\end{tabular}

\section{Breastfeeding History Influences Risk of LRR, DM, and DFS}

We examined the effect of breastfeeding on the probability of LRR, DM, any disease recurrence, and death in this cohort of women with IBC. At 5 years, 
$\mathrm{BF}+$ patients had a significantly lower risk of LRR (9.0\% vs. 23.6\%; $p=0.01$; Figure 1A) and of DM (26.8\% vs. $53.8 \%$; $p=0.008$; Figure 1B) than did BF- patients. Accordingly, there was a significant improvement in 5 -year DFS for BF+ patients (73.1\% vs. $48.1 \%$; $\mathrm{p}=0.006$; Figure 1C) compared with BF- patients. There was a numeric trend towards improved $\mathrm{OS}$ for $\mathrm{BF}+$ patients (79.8\% vs. $59.3 \%$, p=0.10, Figure 1D), although it did not reach statistical significance.

On multivariate analysis, adjusted for age at diagnosis, race/ethnicity, menopausal status, HER2 expression, triple-negative status, grade, stage, rate of pathologic complete response after neoadjuvant therapy, and receipt of adjuvant chemotherapy and endocrine therapy, positive breastfeeding history was associated with significantly improved DFS (Table 3). This effect was driven almost exclusively by a reduced risk of DM (HR 0.38, 95\% CI 0.15-0.97;

A



C

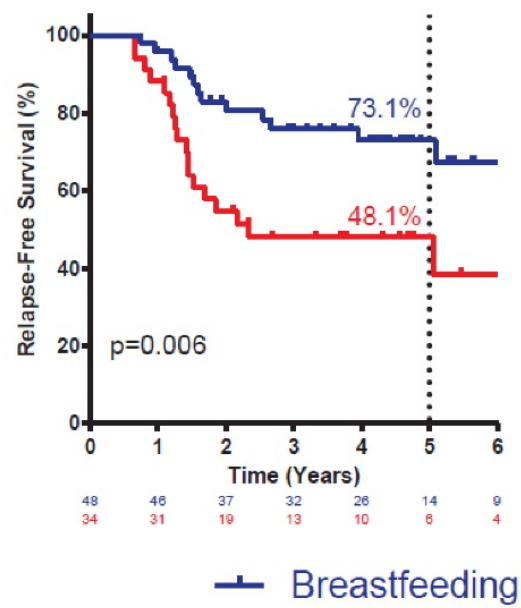

$\mathrm{p}=0.04)$, as there was no effect of breastfeeding on risk of LRR (HR 0.59, 95\% CI 0.13-2.41; $\mathrm{p}=0.43$ ).

Table 3. Multivariate Analysis of Disease-Free Survival

\begin{tabular}{|c|c|c|c|}
\hline Characteristic & Hazard Ratio & $\begin{array}{l}\text { 95\% Confidence } \\
\text { Interval }\end{array}$ & $\mathbf{P}$ \\
\hline Breastfeeding (Yes vs. No) & 0.37 & $0.15-0.93$ & 0.04 \\
\hline Age at Diagnosis $(\geq 50$ vs. $<50)$ & 0.52 & $0.18-1.52$ & 0.29 \\
\hline Race (Non-White vs. White) & 2.24 & $0.91-5.49$ & 0.08 \\
\hline Menopausal Status (Post- vs. Pre) & 1.28 & $0.45-3.62$ & 0.65 \\
\hline Clinical Stage (IIIC vs. IIIB) & 1.18 & $0.53-2.65$ & 0.69 \\
\hline Grade (III vs. I/II) & 0.63 & $0.22-1.83$ & 0.39 \\
\hline $\begin{array}{l}\text { HER2 Status (Positive vs. } \\
\text { Negative) }\end{array}$ & 0.80 & $0.25-2.54$ & 0.71 \\
\hline Triple Negative (Yes vs. No) & 1.25 & $0.37-4.19$ & 0.72 \\
\hline $\begin{array}{l}\text { Pathologic Complete Response } \\
\text { (Yes vs. No) }\end{array}$ & 0.15 & $0.03-0.80$ & 0.03 \\
\hline $\begin{array}{l}\text { Adjuvant Chemotherapy (Yes vs. } \\
\text { No) }\end{array}$ & 0.72 & $0.27-1.92$ & 0.52 \\
\hline $\begin{array}{l}\text { Adjuvant Endocrine Therapy } \\
\text { (Yes vs. No) }\end{array}$ & 0.88 & $0.31-2.50$ & 0.88 \\
\hline
\end{tabular}

\section{B}

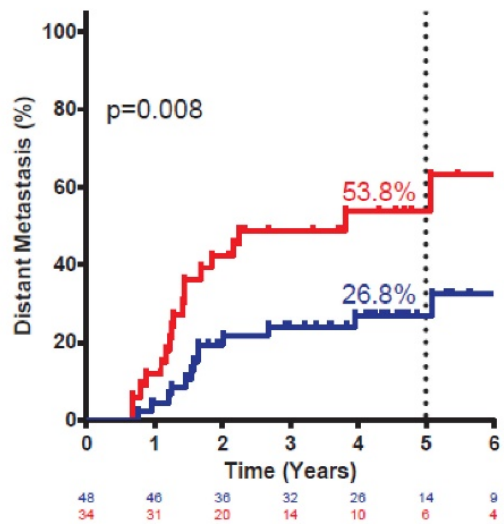

D

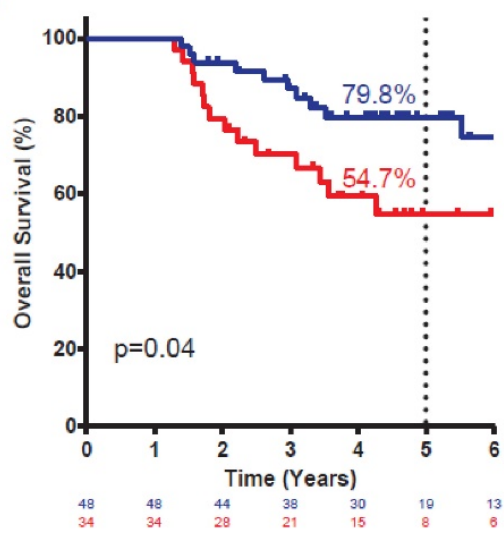

- No Breastfeeding

Figure 1. Actuarial incidence of local recurrence (A) and distant metastasis (B), and disease-free survival (C) and overall survival (D) by breastfeeding history. Statistic is log-rank test. Number at risk at each interval noted below graph. Percentages denote incidence or survival at five years. 




Figure 2. Actuarial disease-free survival in triple-negative IBC patients by breastfeeding history. Statistic is log-rank test. Number at risk at each interval noted below graph. Percentages denote survival at five years.

\section{Breastfeeding History Specifically Modifies Risk of DM for Triple-Negative IBC}

Given the known association between breastfeeding history and risk of basal-like breast cancer, most cases of which are triple-negative, we sought to specifically examine the impact of breastfeeding on DFS in triple-negative IBC. BF+ patients with triple-negative IBC had markedly improved DFS compared with BF- patients with triple-negative IBC (Figure 2). Breastfeeding status did not significantly impact DFS for patients with HER2+ or ER/PR+, HER2- disease (data not shown). Multivariate analysis was not attempted in these subsets owing to the small sample size.

\section{Discussion}

In this prospectively identified cohort of parous women with IBC, we found that a positive breastfeeding history decreases the risks of LRR and DM and, accordingly, that women with a positive breastfeeding history have significantly improved DFS, even after well-defined predictive and prognostic variables are accounted for.

To date, there are no defined molecular alterations or signatures with adequate sensitivity and specificity to discriminate IBC from non-IBC. A potential explanation is that IBC is not a unique molecular entity but rather a manifestation of non-IBC that arises in a microenvironment primed to promote the IBC phenotype [8]. Thus, studies aimed at understanding the IBC microenvironment, and even properties of the normal breast parenchyma that exist before a tumor-initiating event, may illuminate the pathobiology of IBC.

The mammary epithelium undergoes massive expansion during pregnancy, and studies in mice have demonstrated that the abundance of mammary stem cells also increases during this process $[13,14]$. Transformation of these cells is thought to give rise to a population of breast cancer stem cells that incite and perpetuate breast cancer. While pregnancy and breastfeeding have generally been considered protective against the development of breast cancer, the process of involution is known to result in a microenvironment that promotes malignant progression $[15,16]$. A previous study has shown that involution alters the deposition pattern of collagen, and that the involution-associated extracellular matrix promotes growth and dispersion of tumor cells [15]. This aggressive behavior could be mitigated by inhibiting COX-2, suggesting that arachidonic acid metabolism and production of inflammatory mediators during involution drives tumor progression. The expanded stem cell population that results from pregnancy-associated mammary gland hyperplasia, coupled with the pro-inflammatory microenvironment that accompanies involution, may form the cellular basis for the short-term increase in breast cancer incidence that accompanies pregnancy. Interestingly, breastfeeding has specifically been shown to markedly reduce the risk of basal-like breast cancer, a subtype that exhibits molecular features similar to those of mammary stem cells [17-19]. This reduction in risk may suggest that breastfeeding modulates risk of breast cancer predominately by influencing the mammary stem cell pool.

A body of evidence demonstrates that breastfeeding, at least over the long term, protects against the development of basal-like breast cancer, a molecular subtype that is enriched for triple-negative breast cancer and is associated with an aggressive clinical course and poorer prognosis than other subtypes of breast cancer [17-19]. An association between positive breastfeeding history and a lower risk of triple-negative IBC emerged in our cohort as well. However, despite this association, the observed improvement in DFS in breastfeeding patients is not likely explained by the co-linearity of breastfeeding status and development of triple-negative breast cancer, as positive breastfeeding history resulted in the most striking reduction in DM and improvement in DFS among the triple-negative IBC patients.

While the precise mechanisms by which breastfeeding might modulate metastatic potential are unknown, there are several correlative findings from 
the laboratory that may explain our finding. As discussed previously, not breastfeeding appears to result in a persistent population of mammary stem cells within the breast parenchyma. Normal mammary stem cells and breast cancer stem cells alike exhibit markers associated with the epithelial-to-mesenchymal transition, a developmental program characterized by loss of intercellular adhesion, remodeling of the cytoskeleton, and enhanced migration and invasion. Maintenance of the epithelial-to-mesenchymal transition phenotype appears to be critical for breast cancer stem cell self-renewal and for cancer cell invasion and migration and appears to significantly influence response to chemotherapy and radiotherapy [20-23]. Thus, the expanded pool of mammary stem cells associated with not breastfeeding could result in a more robust population of pre-malignant cells with high metastatic potential. Alternatively, we have postulated that the persistent population of mammary stem cells may not explicitly become malignant but instead generate aberrant stem cell niches throughout the normal breast parenchyma that may alter the behavior of a future breast cancer [8]. Epithelial-to-mesenchymal transition in breast cancer stem cells produces soluble factors that stimulate angiogenesis and recruit cancer-promoting myeloid factors, including interleukin 6, interleukin 8, and granulocyte macrophage colony-stimulating factor $[24,25]$. It is conceivable that aberrant mammary stem cell niches may similarly modify the local microenvironment and promote a more aggressive phenotype in malignant cells that arise independently of the expanded stem cell population.

While our results are intriguing, this study does have significant limitations. Although this cohort of subjects was prospectively identified, this analysis is retrospective, of a relatively small number of subjects, with limited ethnic and racial diversity, and at a single institution. Additionally, all epidemiologic data were obtained by questionnaire and, as such, are subject to recall and ascertainment bias. While we do have the total duration of breastfeeding for nearly all patients, we do not have detailed breastfeeding history (e.g., duration of breastfeeding per child). Attempts to analyze breastfeeding as a continuous variable, and dichotomizing our results by receiver operating characteristic analysis, as quartiles, terciles, and above/below the median did not yield meaningful results. Our limited sample size precludes us from analyzing the impact of duration of breastfeeding and speculating about a potential threshold effect.

Although correlative, our data suggest that breastfeeding alters the natural history of IBC. We speculate that involution in the absence of breastfeeding and involution after a sustained period of breastfeeding result in a significantly different cellular and humoral microenvironment that alters the intrinsic risk of developing breast cancer (including IBC) and the behavior of malignancies that do arise. The pre-malignant breast parenchyma should be considered an active participant in the pathobiology of IBC, and a more comprehensive understanding of factors that modify the microenvironment of the mammary gland before a tumor-initiating event is likely to illuminate the unique biology of this disease.

\section{Acknowledgments}

This work was supported by the National Institutes of Health grants R01CA138239-01 and 1R01CA180061-01, the State of Texas Grant for Rare and Aggressive Breast Cancer Research Program, and an institutional research grant from The University of Texas MD Anderson Cancer Center. MD Anderson Cancer Center is supported in part by the National Institutes of Health through Cancer Center Support Grant P30CA016672. B.G.D. is a recipient of Susan G. Komen for the Cure ${ }^{\circledR}$ Postdoctoral Fellowships (KG101478 and KG111387).

\section{Competing Interests}

The authors have declared that no competing interests exist.

\section{References}

1. Bekhouche I, Finetti P, Adelaide J, Ferrari A, Tarpin C, Charafe-Jauffret E, et al. High-resolution comparative genomic hybridization of inflammatory breast cancer and identification of candidate genes. PloS one. 2011; 6: e16950.

2. Bertucci F, Finetti P, Rougemont J, Charafe-Jauffret E, Nasser V, Loriod B, et al. Gene expression profiling for molecular characterization of inflammatory breast cancer and prediction of response to chemotherapy. Cancer research. 2004; 64: 8558-65.

3. Iwamoto T, Bianchini G, Qi Y, Cristofanilli M, Lucci A, Woodward WA, et al. Different gene expressions are associated with the different molecular subtypes of inflammatory breast cancer. Breast cancer research and treatment. 2011; 125: 785-95.

4. Nguyen DM, Sam K, Tsimelzon A, Li X, Wong H, Mohsin S, et al. Molecular heterogeneity of inflammatory breast cancer: a hyperproliferative phenotype. Clinical cancer research : an official journal of the American Association for Cancer Research. 2006; 12: 5047-54.

5. Van der Auwera I, Limame R, van Dam P, Vermeulen PB, Dirix LY, Van Laere SJ. Integrated miRNA and mRNA expression profiling of the inflammatory breast cancer subtype. British journal of cancer. 2010; 103: 532-41.

6. Van Laere SJ, Ueno NT, Finetti P, Vermeulen P, Lucci A, Robertson FM, et al. Uncovering the molecular secrets of inflammatory breast cancer biology: an integrated analysis of three distinct affymetrix gene expression datasets. Clinical cancer research : an official journal of the American Association for Cancer Research. 2013; 19: 4685-96.

7. Woodward WA, Krishnamurthy S, Yamauchi H, El-Zein R, Ogura D, Kitadai $\mathrm{E}$, et al. Genomic and expression analysis of microdissected inflammatory breast cancer. Breast cancer research and treatment. 2013; 138: 761-72.

8. Woodward WA. Inflammatory breast cancer: unique biological and therapeutic considerations. The Lancet Oncology. 2015; 16: e568-76.

9. Anderson KN, Schwab RB, Martinez ME. Reproductive risk factors and breast cancer subtypes: a review of the literature. Breast cancer research and treatment. 2014; 144: 1-10.

10. Atkinson RL, Yang WT, Rosen DG, Landis MD, Wong H, Lewis MT, et al. Cancer stem cell markers are enriched in normal tissue adjacent to triple negative breast cancer and inversely correlated with DNA repair deficiency. Breast cancer research : BCR. 2013; 15: R77.

11. Dawood S, Merajver SD, Viens P, Vermeulen PB, Swain SM, Buchholz TA, et al. International expert panel on inflammatory breast cancer: consensus 
statement for standardized diagnosis and treatment. Annals of oncology : official journal of the European Society for Medical Oncology / ESMO. 2011; 22: 515-23.

12. Hammond ME, Hayes DF, Dowsett M, Allred DC, Hagerty KL, Badve S, et al. American Society of Clinical Oncology/College Of American Pathologists guideline recommendations for immunohistochemical testing of estrogen and progesterone receptors in breast cancer. Journal of clinical oncology : official journal of the American Society of Clinical Oncology. 2010; 28: 2784-95.

13. Asselin-Labat ML, Vaillant F, Sheridan JM, Pal B, Wu D, Simpson ER, et al. Control of mammary stem cell function by steroid hormone signalling. Nature. 2010; 465: 798-802.

14. Huh SJ, Clement K, Jee D, Merlini A, Choudhury S, Maruyama R, et al. Ageand pregnancy-associated DNA methylation changes in mammary epithelial cells. Stem cell reports. 2015; 4: 297-311.

15. Lyons TR, O'Brien J, Borges VF, Conklin MW, Keely PJ, Eliceiri KW, et al. Postpartum mammary gland involution drives progression of ductal carcinoma in situ through collagen and COX-2. Nature medicine. 2011; 17: 1109-15.

16. Lyons TR, Schedin PJ, Borges VF. Pregnancy and breast cancer: when they collide. Journal of mammary gland biology and neoplasia. 2009; 14: 87-98.

17. Islami F, Liu Y, Jemal A, Zhou J, Weiderpass E, Colditz G, et al. Breastfeeding and breast cancer risk by receptor status-a systematic review and meta-analysis. Annals of oncology : official journal of the European Society for Medical Oncology / ESMO. 2015; 26: 2398-407.

18. Millikan RC, Newman B, Tse CK, Moorman PG, Conway K, Dressler LG, et al. Epidemiology of basal-like breast cancer. Breast cancer research and treatment. 2008; 109: 123-39.

19. Palmer JR, Boggs DA, Wise LA, Ambrosone CB, Adams-Campbell LL, Rosenberg L. Parity and lactation in relation to estrogen receptor negative breast cancer in African American women. Cancer epidemiology, biomarkers \& prevention : a publication of the American Association for Cancer Research, cosponsored by the American Society of Preventive Oncology. 2011; 20: 1883-91.

20. Mani SA, Guo W, Liao MJ, Eaton EN, Ayyanan A, Zhou AY, et al. The epithelial-mesenchymal transition generates cells with properties of stem cells. Cell. 2008; 133: 704-15.

21. Creighton CJ, Chang JC, Rosen JM. Epithelial-mesenchymal transition (EMT) in tumor-initiating cells and its clinical implications in breast cancer. Journal of mammary gland biology and neoplasia. 2010; 15: 253-60.

22. Blick T, Hugo H, Widodo E, Waltham M, Pinto C, Mani SA, et al. Epithelial mesenchymal transition traits in human breast cancer cell lines parallel the CD44(hi/)CD24 (lo/-) stem cell phenotype in human breast cancer. Journal of mammary gland biology and neoplasia. 2010; 15: 235-52.

23. Dave B, Mittal V, Tan NM, Chang JC. Epithelial-mesenchymal transition, cancer stem cells and treatment resistance. Breast cancer research : BCR. 2012; 14: 202.

24. Suarez-Carmona M, Bourcy M, Lesage J, Leroi N, Syne L, Blacher S, et al. Soluble factors regulated by epithelial-mesenchymal transition mediate tumour angiogenesis and myeloid cell recruitment. The Journal of pathology. 2015; 236: 491-504.

25. Brysse A, Mestdagt M, Polette M, Luczka E, Hunziker W, Noel A, et al. Regulation of CXCL8/IL-8 expression by zonula occludens-1 in human breast cancer cells. Molecular cancer research : MCR. 2012; 10: 121-32. 